therapy with conventional disease-modifying anti-rheumatic drugs (cDMARD). Data comparing CDMARD and TNFi in clinical trial settings are common, but there is limited published real-world evidence on their comparative effectiveness.

Objectives: Compare disease status and outcomes in UK patients with RA receiving cDMARD vs TNFi.

Methods: Data derive from Adelphi's RA Disease Specific Programme 2017, a cross-sectional survey of 49 UK rheumatologists providing information on demographics, disease history, disease status and treatment of patients with RA. All patients $(n=640)$ were included in the RA treatment analysis; patients were included in the comparative analysis if at the time of survey they had been receiving current treatment for at least 3 months, with either cDMARD (and had never received biologic(b)DMARD), or a TNFi (and had never received prior bDMARD). A propensity score based on BMI, duration on current therapy, RA severity and disease duration at initiation of current therapy was used to match treatment groups. Using Abadie-Imbens standard errors, clinical characteristics and measures of disease activity were compared between the matched groups.

Results: Current therapy of 640 patients: 379 (59.2\%) bDMARD, of which 253 (66.8\%) were receiving TNFi; 212 (33\%) cDMARD; $18(2.8 \%)$ had never received any DMARD, 15 (2.3\%) had discontinued bDMARD. Mean DAS28 at initiation of therapy was 4.94 in overall cDMARD and 5.77 in TNFi groups. Table 1 shows the comparative analysis of cDMARD vs TNFi matched treatment groups. The CDMARD group had a higher proportion of moderate/severe and active/very active disease at time of survey, a higher proportion of patients in this group had no improvement in disease severity or activity since initiation of current therapy, and they were less likely to have achieved a EULAR response. A higher proportion of CDMARD patients and physicians were not satisfied with their disease control. Mean DAS28 scores at time of survey had declined from time of initiation of therapy to time of survey in matched cDMARD vs TNFi groups, from 5.27 to 3.1 vs 5.77 to 2.7 respectively.

Table 1

\begin{tabular}{|c|c|c|c|}
\hline & $\%$ & $\%$ & $P=$ \\
\hline \multicolumn{4}{|l|}{ Physician reported current disease status } \\
\hline Moderate or severe & 43.5 & 22.4 & 0.02 \\
\hline ‘Active' or 'very active' disease & 58.8 & 44.1 & 0.10 \\
\hline \multicolumn{4}{|l|}{$\begin{array}{l}\text { Change in disease status since initiation of current } \\
\text { treatment }\end{array}$} \\
\hline 'No improvement' in severity & 25.3 & 7.7 & 0.04 \\
\hline ‘No improvement' in disease activity ${ }^{1}$ & 22.0 & 7.7 & 0.08 \\
\hline Not achieved EULAR response (based on DAS28) ${ }^{2}$ & 16.0 & 6.9 & 0.08 \\
\hline \multicolumn{4}{|l|}{ Satisfaction with current disease control } \\
\hline Physicians 'not satisfied' & 39.4 & 8.2 & $<0.01$ \\
\hline Patients 'not satisfied' 3 & 31.7 & 16.7 & 0.35 \\
\hline
\end{tabular}

Lower sample size due to missing values: ${ }^{1}$ cDMARD 147, TNFi $168 ;{ }^{2}$ cDMARD 75, TNFi 131; ${ }^{3}$ cDMARD 54, TNFi 60

Conclusions: UK patients with RA receiving cDMARD have poorer outcomes, in terms of measured disease status and control, than their matched counterparts receiving TNFi. Despite having a higher mean DAS score at initiation, patients in the TNFi group had a lower mean score at time of survey than patients receiving cDMARD. This real-world evidence highlights the continued utility of TNFi as effective treatments for patients with RA. Potential benefit of early TNFi initiation merits further research.

Disclosure of Interest: J. Addison Shareholder of: Biogen, Employee of: Biogen, S. Lobosco Employee of: Adelphi Real World, B. Hoskin Employee of: Adelphi Real World, E. Sullivan Employee of: Adelphi Real World, J. Pike Employee of: Adelphi Real World, S. Fenwick Shareholder of: Biogen, Employee of: Biogen DOI: 10.1136/annrheumdis-2018-eular.5812

\section{SAT0206 \\ RESULTS OF THE ALTERRA CLINICAL TRIAL - THE EFFICACY OF THE ALTERNATIVE DOSING REGIMEN FOR RITUXIMAB BIOSIMILAR IN BDMARDS NAIVE PATIENTS WITH RHEUMATOID ARTHRITIS}

V. Mazurov ${ }^{1}$, L. Denisov ${ }^{2}$, I. Gordeev ${ }^{3}$, O. Nesmeyanova ${ }^{4}$, T. Plaksina ${ }^{5}$, E. llivanova ${ }^{6}$, D. Krechikova ${ }^{7}$, E. Zonova ${ }^{8}$, L. Knyazeva ${ }^{9}$, A. Artemeva ${ }^{10}$, E. Dokukina ${ }^{10}, \mathrm{E}$. Chernyaeva ${ }^{10}, \mathrm{R}$. Ivanov ${ }^{10} .{ }^{1}$ North-Western State Medical University named after I.I. Mechnikov, Saint-Petersburg, ${ }^{2}$ V.A. Nasonova Research Institute of Rheumatology, ${ }^{3}$ O.M. Filatov City Clinical Hospital №15, Moscow, ${ }^{4}$ Chelyabinsk Regional Clinical Hospital, Chelyabinsk, ${ }^{5}$ N.A. Semashko Nizhniy Novgorod Regional Clinical Hospital, Nizhniy Novgorod, ${ }^{6}$ Leningrad Regional Clinical Hospital, Saint-Petersburg, ${ }^{7}$ The Department Hospital at Smolensk Station of the open JSC "Russian Railways", Smolensk, ${ }^{8}$ Novosibirsk State Medical University, Novosibirsk, ${ }^{9}$ Kursk Reginal Clinical Hospital, Kursk, ${ }^{10}$ JCS BIOCAD, Saint-Petersburg, Russian Federation

Background: Rituximab (RTX) is successfully used in patients with active rheumatoid arthritis (RA) who previously received biological disease-modifying antirheumatic drugs (bDMARDs) at a dose of $1000 \mathrm{mg}$. Previous preclinical and clinical studies showed that BCD-020 is highly similar to innovator RTX. ALTERRA study demonstrated that first-line use of $600 \mathrm{mg} \mathrm{BCD-020}$ is very effective in bDMARDs naive patients with RA

Objectives: The goal of ALTERRA study was to evaluate the efficacy and safety of the alternative dosing regimen $(600 \mathrm{mg})$ of BCD-020 in bDMARDs naive patients with RA

Methods: ALTERRA study was conducted as multicenter randomized doubleblind placebo-controlled phase 3 study. After the screening patients were stratified by age, anti-CCP level and DAS28 score, randomized (2:1) into 2 arms and received BCD-020 (in combination with methotrexate (MTX)) in a dose $600 \mathrm{mg}$ IV or placebo (in combination with MTX) on day 1 and day 15 , then, if the activity of arthritis persisted after 24 wks of study, a second course was provided. Patients were observed up to 52 wks.

Results: A total of 159 patients were enrolled in ALTERRA study, 107 patients in BCD-020 arm and 52 patients in placebo arm.

Efficacy: ACR20 at wk 24 was reached by $65.69 \%$ of patients in BCD-020 arm and $29.41 \%$ in placebo arm ( $p=0.00005$, the difference in proportion of registration ACR20 with $95 \% \mathrm{Cl}$ was 29.41 [19.27\%; 53.28\%], margin $10.5 \%$ ) in per protoco population, so hypothesis of superiority was confirmed. The performed analysis showed a much more pronounced decrease in the DAS28-4 (ESR) index in BCD 020 arm compared with placebo arm $(\mathrm{p}=0.0006)$ at wk 24. A much more significant decrease in change of the HAQ-DI index was also shown in the BCD-020 arm $(p=0.008)$. Analysis of efficacy at wk 52 showed the preservation of the response after 2 courses of therapy with BCD-020, $600 \mathrm{mg}$ (in combination with MTX): ACR20 reached by $84.5 \%$, ACR50 - by $54.6 \%$, ACR70 - by $29.9 \%$ of patients.

Safety: BCD-020 showed a favorable safety profile with no significant difference with placebo use (in combination with MTX). After 24 wks patients of both groups developed high similar level of related adverse events: $16.8 \%$ of patients in BCD 020 arm and $11.76 \%$ in placebo arm $(p=0.555)$. There were only 3 cases of severe adverse events (2.8\%) in BCD-020 arm and 2 cases (3.92\%) in placebo group From wk 24 to wk 52: $13.08 \%$ of patients (who received 2 courses of BCD-020) and $19.61 \%$ of patients (who received one course of BCD-020 after 24 wk) developed related adverse events.

Figure 1 ACR 20/50/70 in bDMARDs naive patients with RA after 24-wk treatment of BCD020/placebo (in combination with MTX)

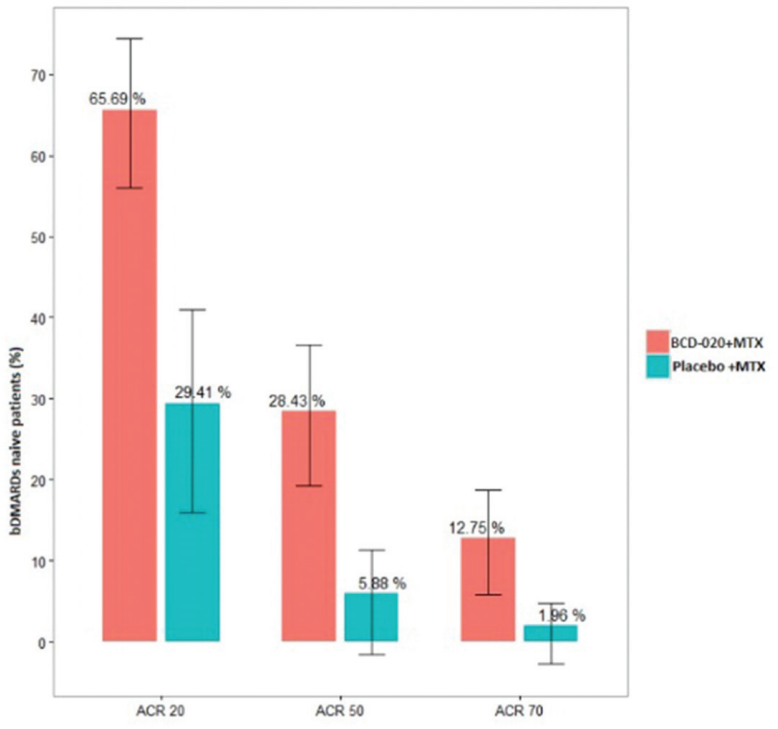

Conclusions: ALTERRA study showed high efficacy and favorable safety profile of RTX biosimilar BCD-020 at a dose of $600 \mathrm{mg}$ in combination with MTX in bDMARDs naive patients with RA

Disclosure of Interest: V. Mazurov: None declared, L. Denisov: None declared, I. Gordeev: None declared, O. Nesmeyanova: None declared, T. Plaksina: None declared, E. Ilivanova: None declared, D. Krechikova: None declared, E. Zonova: None declared, L. Knyazeva: None declared, A. Artemeva Employee of: JSC BIO CAD, E. Dokukina Employee of: JSC BIOCAD, E. Chernyaeva Employee of: JSC BIOCAD, R. Ivanov Employee of: JSC BIOCAD DOI: 10.1136/annrheumdis-2018-eular.2300 